\title{
Butterfly design mesh antenna of optical rectenna for S-band communication systems
}

\author{
Chokri Baccouch $^{1}$, Chayma Bahhar ${ }^{2}$, Hèdi Sakli ${ }^{3}$, Nizar Sakli ${ }^{4}$ \\ 1,2,3 MACS Research Laboratory, National Engineering School of Gabes, Gabes University, Tunisia \\ ${ }^{3,4}$ EITA Consulting 5 Rue du Chant des oiseaux, France
}

\begin{tabular}{l} 
Article Info \\
\hline Article history: \\
Received Mar 12, 2020 \\
Revised Jun 23, 2020 \\
Accepted Jul 12, 2020 \\
\hline Keywords: \\
Communication systems \\
Microwaves \\
Patch antenna \\
Rectenna \\
Solar cell
\end{tabular}

\begin{abstract}
A novel optical rectenna design is presented in this paper to operate in Sband communication. We propose a new method of combining antennas and solar cells to collect and transmit optical and radio frequency signals respectively. In this work, we determined the electrical power collected, it can be used for the polarization of a diode or a low-noise amplifier in a receiver block thus simulation results provides a gain of $6.74 \mathrm{dBi}$ at $2.9 \mathrm{GHz}$ with an effective return loss of $-33.62 \mathrm{~dB}$ and radiated power of $7.08 \mathrm{~mW}$. These good results make it possible to use the antenna particularly in pointto-point communication systems. A three topologies of rectifying circuits are proposed in the present work. The parametric study has been shown that the efficiency RF/DC conversion can reach $66 \%$ for an input power of $10 \mathrm{dBm}$ and a load resistance of $3 \mathrm{k} \Omega$.
\end{abstract}

This is an open access article under the CC BY-SA license.

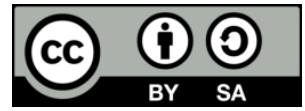

\section{Corresponding Author:}

Chokri Baccouch

MACS Research Laboratory

National Engineering School of Gabes, Gabes University

Gabes, 6029, Tunisia

Email: chokri.baccouch13@gmail.com

\section{INTRODUCTION}

Recent years, the energy feeding problem for many communications systems can be solve by the RF energy harvesting and conversion into direct current. Rectenna, or a rectifying antenna as it is popularly known, is one such means of technology for recovering that energy. The antenna choice, an essential element, for rectenna system is very important. The development of space telecommunications controls and remote controls, have led to the growing need for inexpensive and space-saving antennas using simple and cost-effective technology [1]. It is therefore desirable to design devices that can harvest energy from their environment by reducing the load on the power grid and reducing operating costs [2].

Recently, integrated communication systems with photovoltaic technology for low cost and standalone applications have received a lot of attention. The integration of microwave antennas and solar cells offers a number of advantages for satellite and terrestrial applications [3]. A stand-alone remote base station is such an application where PV technology can be used. But these devices often involve the use of solar cells and separate antennas, which necessitates a compromise in using the limited available surface. The integration of the base station antennas with the photovoltaic cells can provide a compact and reliable solution [4]. Rigorous analysis is always desirable to design antennas in the energy harvesting environment to maintain the desired overall performance of the dual-function system of energy harvesting and RF transmission simultaneously [5]. 


\section{SOLAR CELL ANTENNA}

\subsection{Basic considerations}

Many methods to realize high-performance antennas integrated with solar cells have been studied, but the problem of surface limitation has not resolved with the method of integration [6-8]. These return to the solar cell placement above the antenna element or underneath the antenna element. The minimization of blocking of the solar radiation and the maximization of the solar efficiency are due to the location of the solar cells above the elements of the antenna. A complicated power supply structure to isolate the RF and DC outputs that may be difficult to produce at low pressure and costly is required.

Otherwise, the location of the solar cells under the antenna elements reduces solar efficiency, but can improve the RF performance of the antenna. In this case, where we focused our study between minimizing reduction in solar efficiency and improving RF performance. Therefore, in order to remedy the problem of surface limitation, here we propose a new type of solar cell antenna with a mesh patch printed on a silicon substrate with an $\mathrm{SiO}_{2}$ insulating layer, it is an optically transparent hybrid system. A higher operating frequency, an ability to operate at low voltage and low power consumption and insensitivity to the effects of ionizing radiation can be obtained when we used the silicon on an insulating layer $\mathrm{SiO}_{2}$.

It is not a integration of patch antenna with a solar cell. The method used here it is a hybridization of solar cell antenna utilize to combine both microwave and optical signals. This method solves the major problem of surface limitation, compared to a simple integration, with good performances DC and RF [9-11].

\subsection{Optimal design}

The main goal of optimal design for this solar cell antenna has been studied to minimize the power losses of the solar cell antenna and improve the conversion efficiency as a solar cell. We determine the maximum electrical power collected as a function of finger width and the optimal finger width $W_{f}$ has been used for the design of the meshed patch [12]. Two types of waves can exist with this mesh structure. The optical waves that will be absorbed by the silicon (semiconductor) and the RF waves that will be collected by the mesh patch metal. Table 1 show the dimensions of the proposed design. The proposed structure of solar cell antenna printed on a multi-layered substrate show in Figure 1. While the proposed design of solar cell antenna is given in Figure 2. A microstrip line of characteristic impedance equal to $50 \Omega$ is used to power the proposed solar cell antenna. The simulation complexity and the high computation time are due to the use of substrate with thin films.

Table 1. The dimensions of the solar cell antenna

\begin{tabular}{cc}
\hline Parameters & Values \\
\hline$W_{b}$ & $0.5 \mathrm{~mm}$ \\
$W_{f}$ & $60 \mu \mathrm{m}$ \\
$L$ & $18.2 \mathrm{~mm}$ \\
$W$ & $0.235 \mathrm{~mm}$ \\
\hline
\end{tabular}

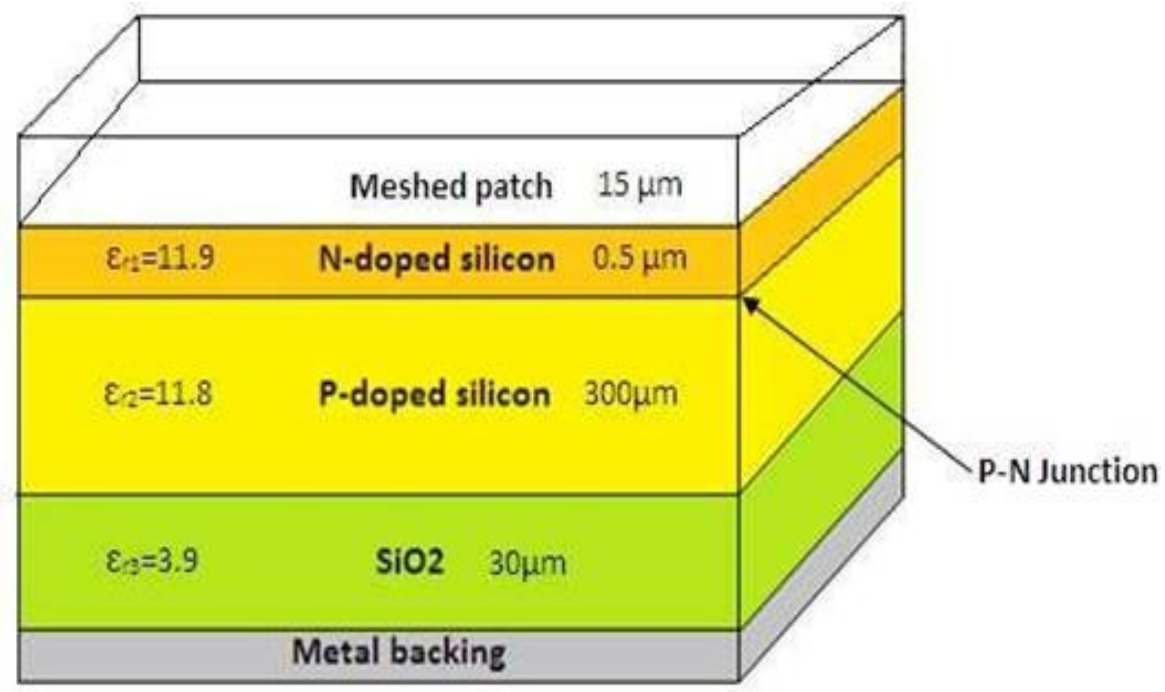

Figure 1. Multi-layered substrate of solar cell antenna 


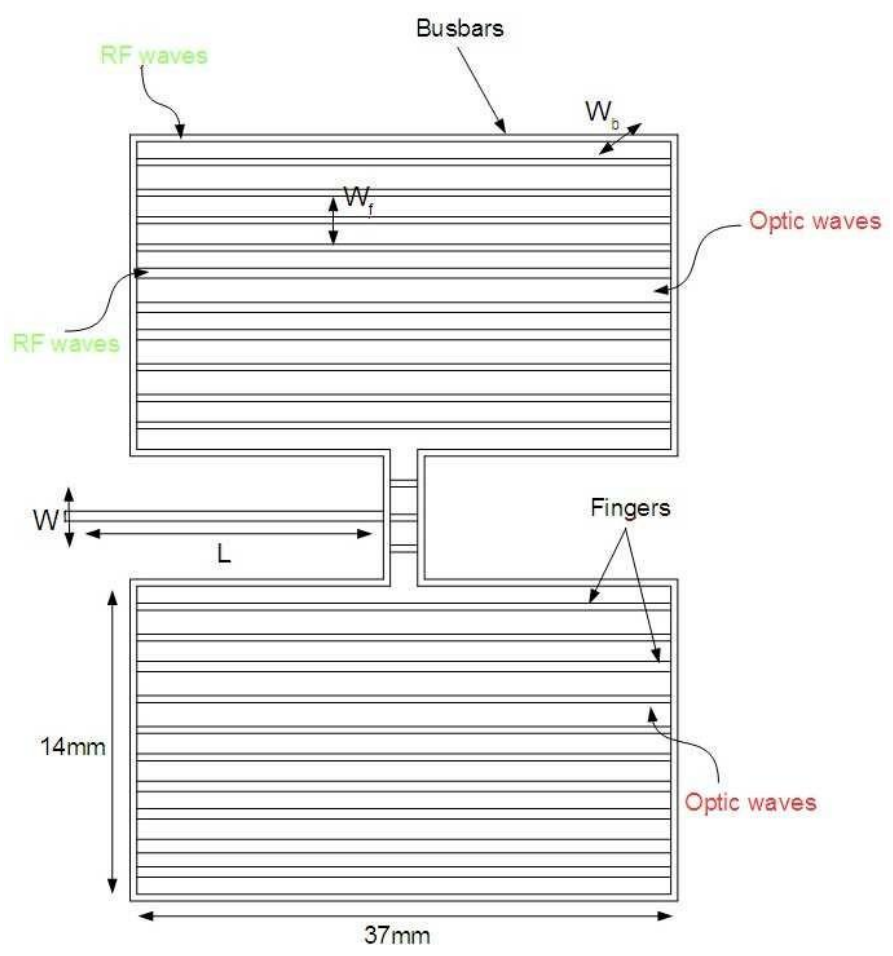

Figure 2. Solar cell antenna design

\section{RESULTS AND DISCUSSIONS}

The simulation results show that this designed solar cell antenna can be used at $2.9 \mathrm{GHz}$ with an effective return loss of $S 11=-33.62 d B$ as shown in Figure 3. To the normal scale, only $0.043 \%$ of the emitted power will be reflected as well as the impedance $Z_{a}=49.6 \Omega$ which confirms the adaptation of the antenna. Thus to evaluate this adaptation, the VSWR is a important parameter of performance measurement at the input of the antenna must be studied. This is indicates the signal reflection due to a mismatch between the impedance of the antenna and that of the source. The reflected signal leads to the appearance of the standing wave voltage in the power supply line which, in turn, destroys the reliability of the antenna [13]. For this solar cell antenna, the obtained VSWR is equal to 1.008. The ideal value of VSWR is 1 which means that $100 \%$ of the delivered power is accepted (no reflection). But, practically speaking, it is tolerable up to 2.

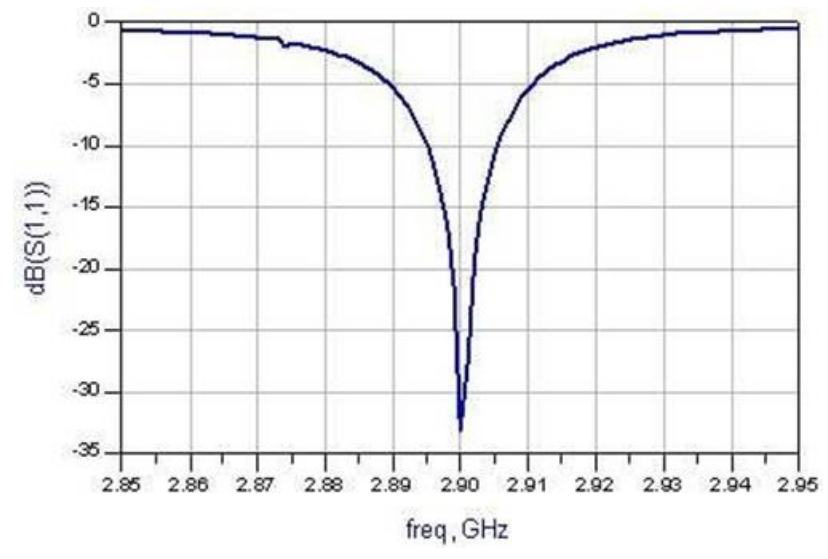

Figure 3. Reflection coefficient S11

To have a good radiation, the correct values of S11 and VSWR are not sufficient. An important metric must be taken into account when designing an antenna, and that is gain. The radiation pattern in the horizontal plane and the radiation pattern in the $\mathrm{E}$ and $\mathrm{H}$ plane are given in Figures 4, 5(a) and 5(b),

Butterfly design mesh antenna of optical rectenna for S-band communication systems (Chokri Baccouch) 
respectively. Since it is a symmetrical structure, the radiation of our antenna is collected in two main lobes whose amplitude is much higher than that of the lateral lobes which are practically nil, and which have a wide beam width at $-3 \mathrm{~dB}$. The total directivity of this highly directional radiation at $2.9 \mathrm{GHz}$ is $8.12 \mathrm{~dB}$, and the antenna gain describes the energy transmitted to that of an isotropic source along the direction of the radiation peak. The values obtained of the radiated power and of the gain are $7.08 \mathrm{~mW}$ and $6.74 \mathrm{dBi}$ respectively is shown in Figure 6. These good results make it possible to use the antenna in particular in point-to-point transmission systems.

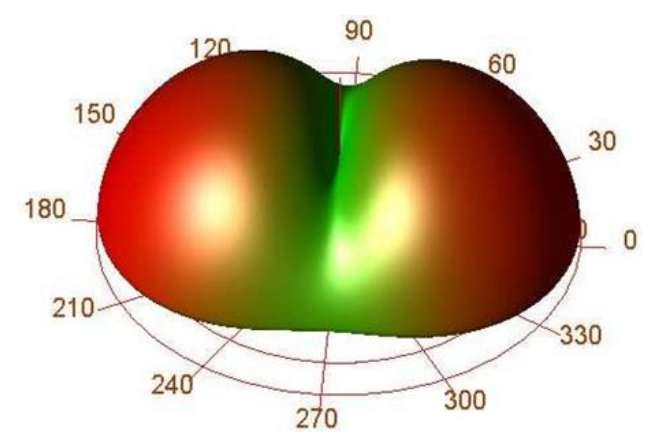

Figure 4. Radiation pattern

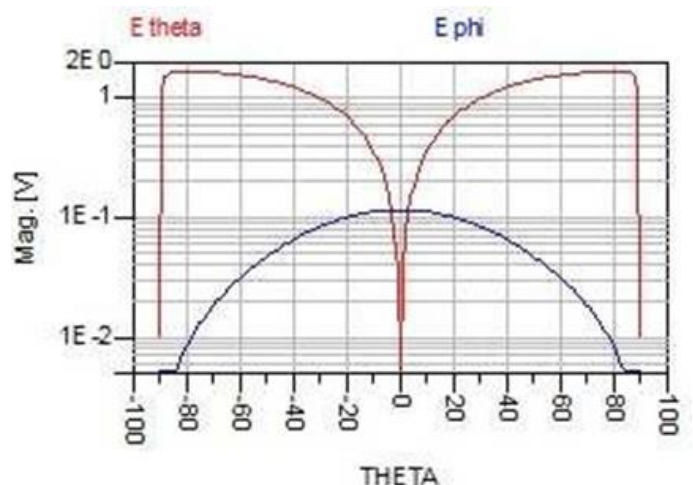

(a)

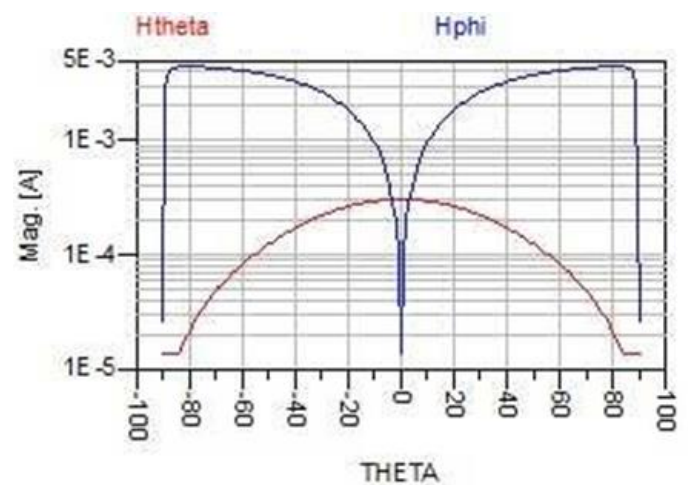

(b)

Figure 5. Far field radiation pattern, (a) in E plane, (b) in H plane

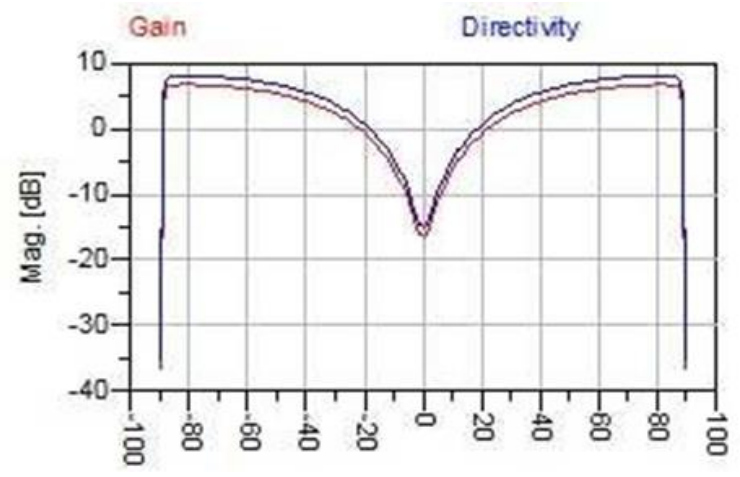

Figure 6. Directivity and gain

We propose an RF/DC decoupling circuit for solar cell antenna illustrated in Figure 7. The RF signals must be decoupled from the DC signal, they must not be interfered. Figure 8 shows the obtained result. 


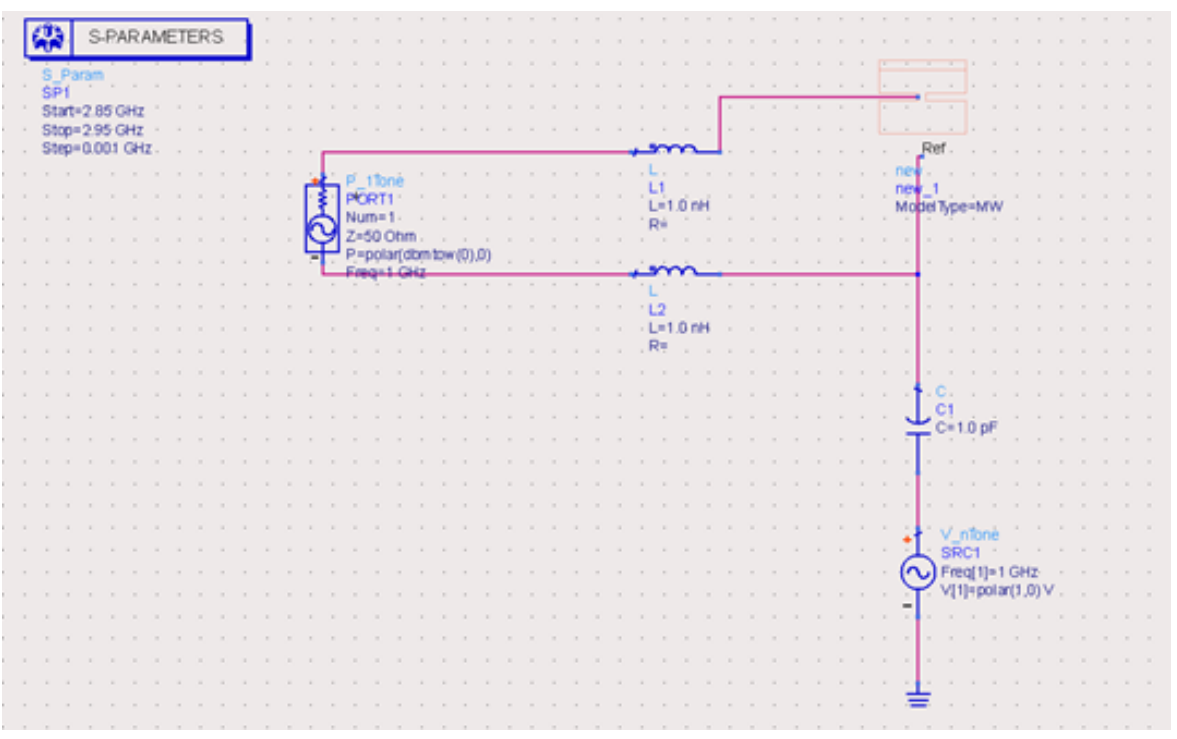

Figure 7. RF/DC decoupling circuit proposed

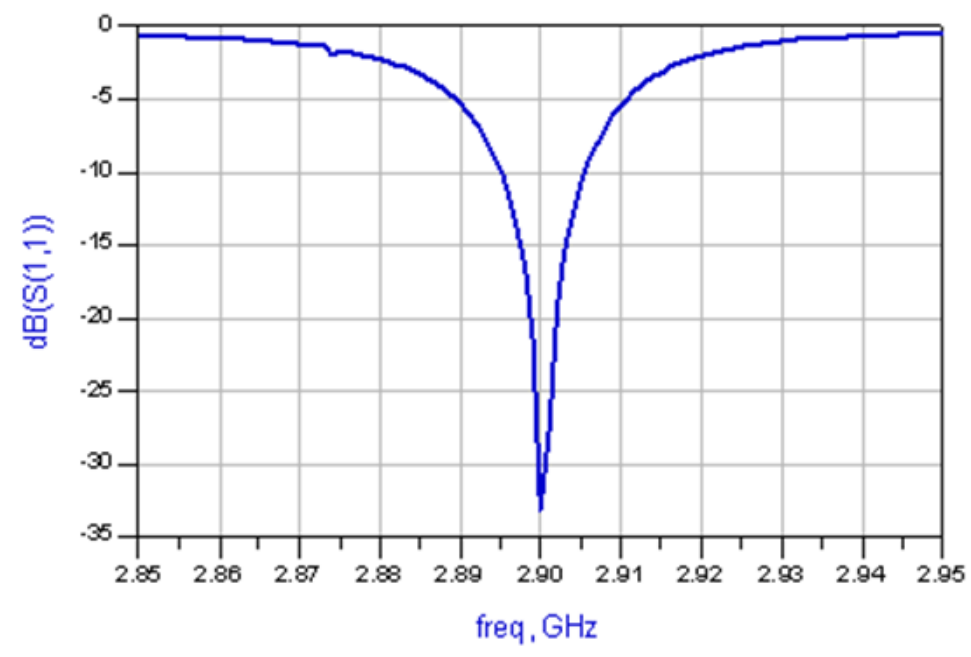

Figure 8. Simulation result of parameter reflection S11

\section{RECTENNA GLOBAL STRUCTURE}

The main role of a rectifying antenna, or rectenna as it is popularly known, is to recolt, from free space, RF waves and convert it into direct current [14-18]. In this work, we studied a optical rectenna based on a solar cell antenna dedicated to energy harvesting and RF transmission at the same time. The optical waves will be transmitted in the form of DC signals and the electromagnetic waves will be divided into two parts, one part contains the transmitted data and the other non-usable part will be filtered, by a bandpass filter allowing only one band to pass or frequency interval between [2.895 GHz-2.905 GHz], and converted by the rectifier circuit into DC signals, as shown in Figure 9. The conversion circuit converts the part not usable from RF waves into a DC signal. A HF low-pass filter, a RF-DC conversion circuit and a DC load circuit composed the chained of rectifier circuit. The function of the high frequency low pass filter is: on the one hand, it avoids the harmonics generated by the Schottky diode; on the other hand, it performs the impedance matching between the antenna of the solar cell and the rectifier. On the other side of the conversion circuit, there is a DC filter whose principle is to ensure the impedance matching between the rectifier circuit and the resistive load, it is a low pass filter [19-25]. Single stage voltage multiplier, two stage voltage multiplier topologies and series topology, shown in Figure 10, are three different rectifier topologies proposed in this work. 


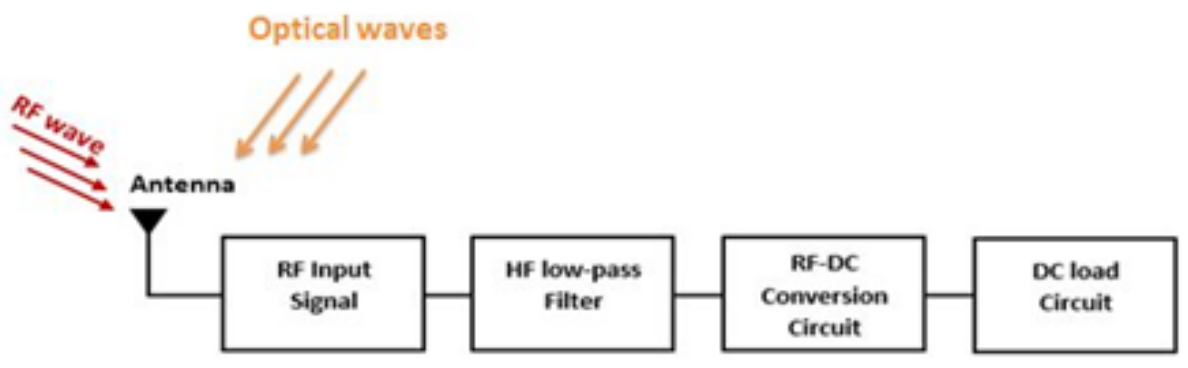

Figure 9. Global structure of optical rectenna system

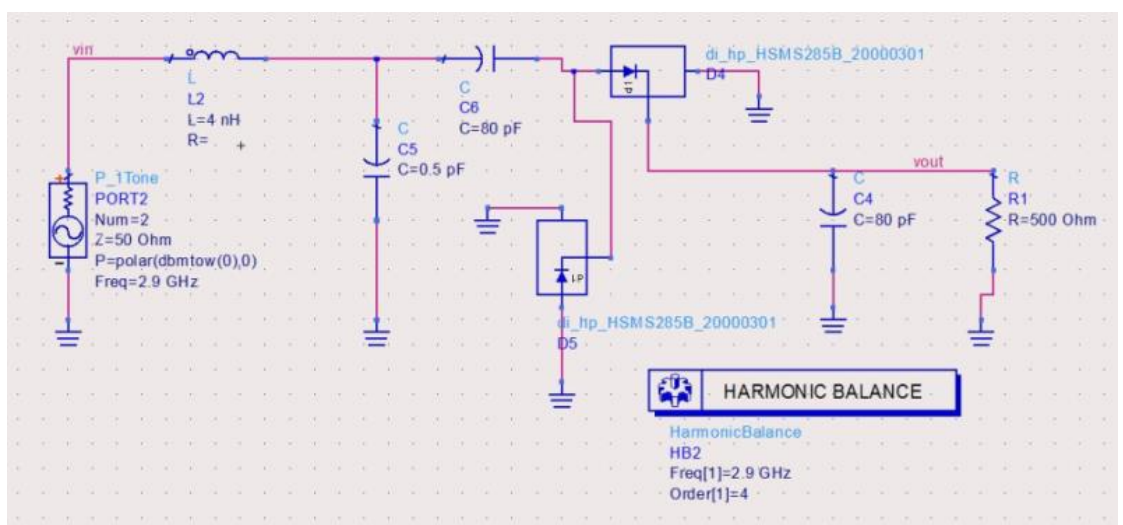

(a)

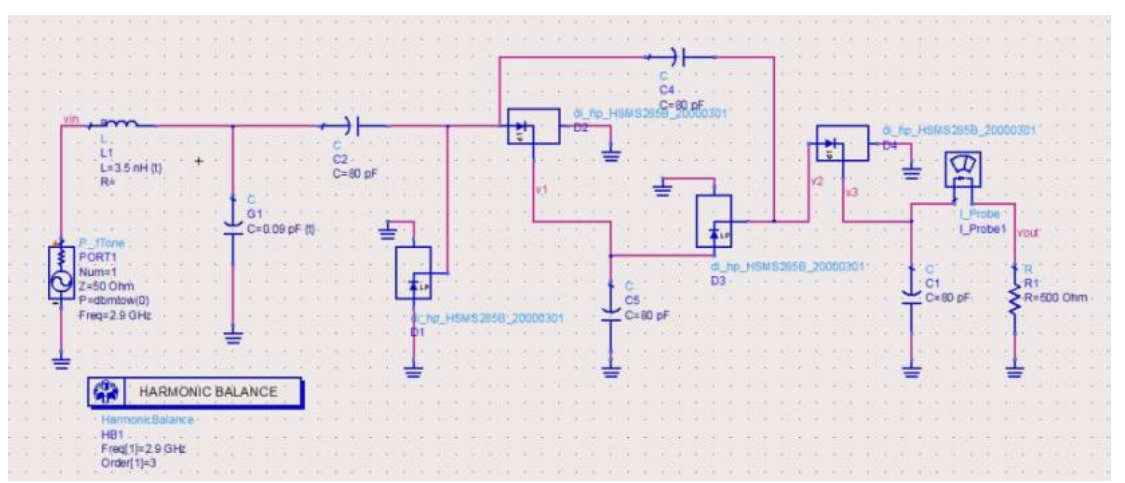

(b)

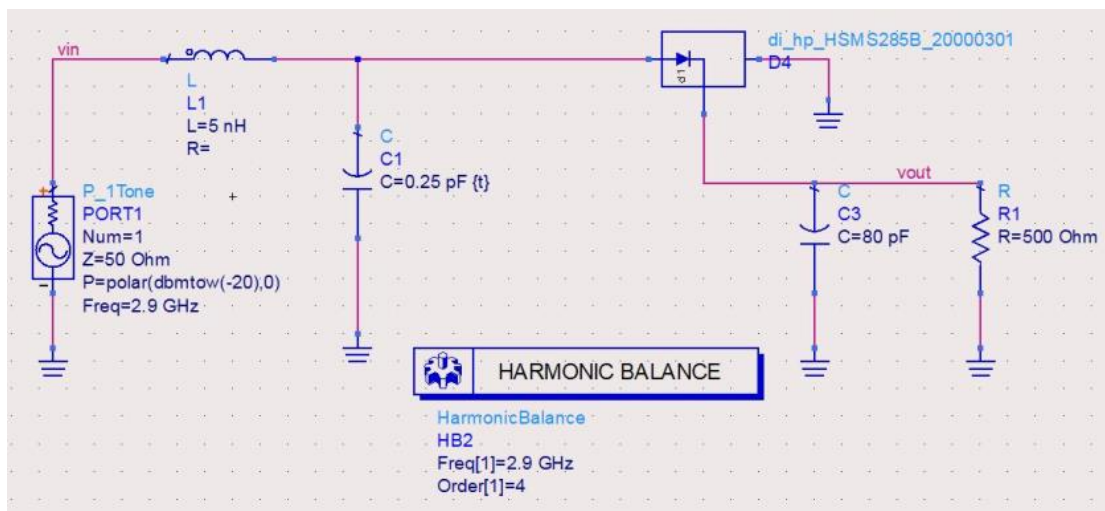

(c)

Figure 10. Rectifier circuit topology, (a) single stage voltage multiplier topology, (b) two stage voltage multiplier topology, (c) series topology 
The main objective of the rectenna optical system is to improve the efficiency of converting RF waves into direct current. The performance of the rectenna can be studied as:

$$
\eta=\frac{P_{D C}}{P_{R F}}=\frac{V_{D C}^{2}}{P_{R F} \cdot R_{L}}
$$

With

$P_{R F}:$ Input RF power

$P_{D C}:$ Output DC power

$R_{L} \quad$ : The resistive load

$V_{D C}:$ Output DC

For a fixed RF input power in the order of $0 \mathrm{dBm}$, we investigated the influence of the resistance load value on the conversion efficiency. For a load resistance of 500, the series topology can provide the best conversion efficiency of about $49.8 \%$, as shown in Figure 11 . Under the smallest load resistance of $1 \mathrm{k} \Omega$, the best efficiency of the single-stage voltage doubler topology is $28.27 \%$. However, the existing two-stage voltage multiplier topology can achieve a higher DC output voltage of up to $1.158 \mathrm{~V}$.

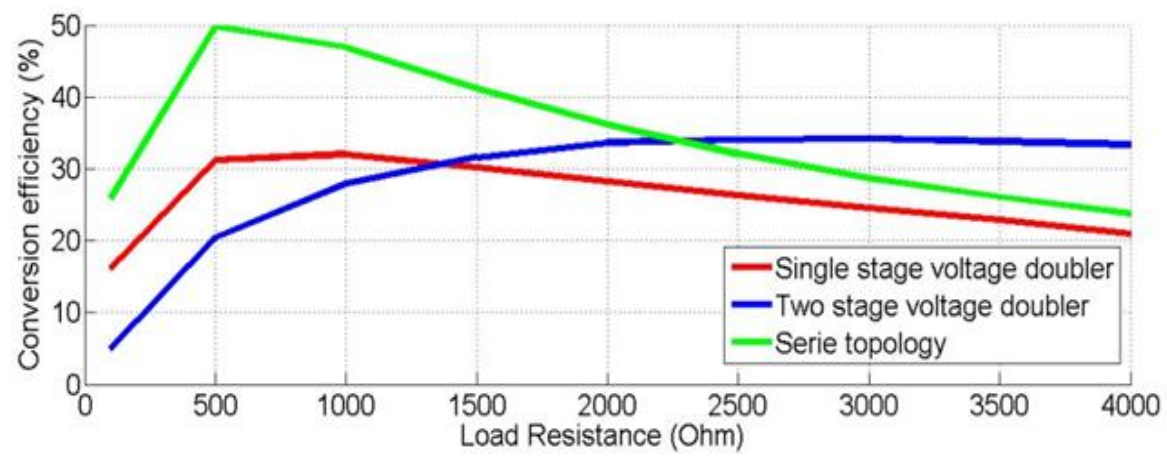

Figure 11. The relationship between the conversion efficiency of different rectifier topologies and the load resistance

Figure 12 shows the relationship between the conversion efficiency of different rectifier topologies and the RF input power. We have fixed the value of the load resistance at $500 \Omega$. We have noticed that the best conversion efficiency that can be obtained with a two-stage voltage multiplier topology is $-20 \mathrm{dBm}$ to $20 \mathrm{dBm}$. For an RF input power of $5 \mathrm{dBm}$ and a load resistance of $500 \Omega$, this efficiency reaches a maximum of $90 \%$.

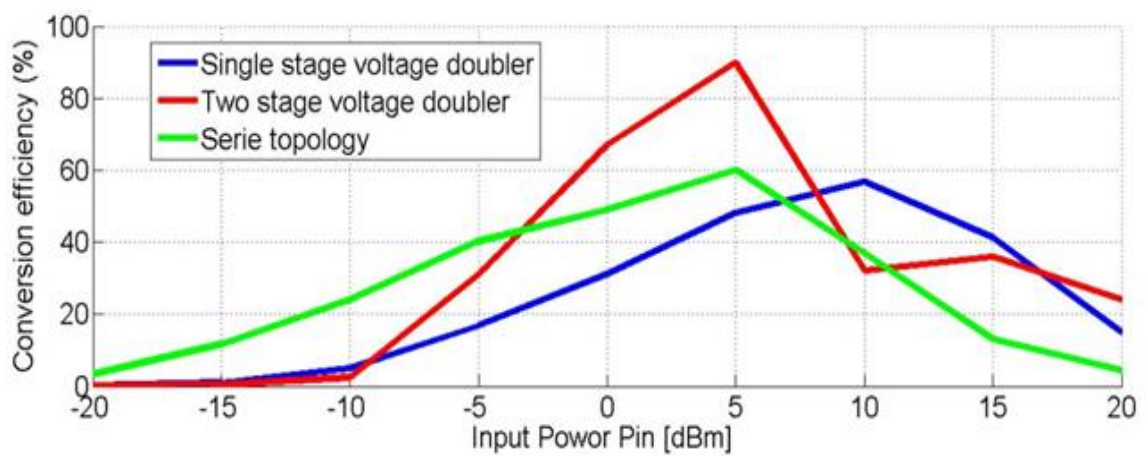

Figure 12. The relationship between the conversion efficiency of different rectifier topologies and the input RF power 


\section{CONCLUSION}

In this work, we presented a optical rectenna with a solar cell antenna dedicated at a time to energy harvesting and RF transmission. This method allowed us to evaluate the performance of a new model of combination solar cell and antenna which is very advantageous and practical. We conclude that a solar cell antenna of linear structure is more efficient, as a solar cell (maximum electric power collected) or as an antenna (gain, directivity, radiated power...), compared to that of a crossed structure which we have already studied in another work. On the other hand, three topologies of rectifier circuits for rectenna optical systems have been proposed. The results show that the best conversion efficiency can be obtained using the two-stage voltage doubler rectification topology, which is $66 \%$.

\section{ACKNOWLEDGEMENTS}

The authors would like to acknowledge their research laboratory for all effort made to be better at each published work.

\section{REFERENCES}

[1] C. Baccouch, et al., "New optically transparent hybrid system for satellite and terrestrial communications," 5ème Conférence Internationale des Energies Renouvelables (CIER-2017) Proceeding of Engineering and TechnologyPET, vol. 27, 2017, pp. 92-95.

[2] N. Henze, et al., "Investigations on planar antennas with photovoltaic solar cells for mobile communications," in IEEE International Symposium on Personal, Indoor and Mobile Radio Communications (PIMRC), vol. 1, 2004, pp. 622-626.

[3] T. W. Turpin and R. Baktur, "Meshed patch antennas integrated on solar cells," IEEE Antennas Wireless Propagation Letter, vol. 8, pp. 693-696, 2009.

[4] Maharaja M. and Kalaiselvan C., "Integration of Antenna and Solar Cell for Satellite and Terrestrial Communication," International Journal of Scientific and Research Publications, vol. 3, no. 5, pp. 1-5, 2013.

[5] C. Baccouch, et al., "Patch antenna based on a photovoltaic solar cell grid collection," 2016 Progress in Electromagnetic Research Symposium (PIERS), 2016, pp. 164-165.

[6] C. Baccouch, et al., "Patch Antenna based on a Photovoltaic Cell with a Dual resonance Frequency," Advanced Electromagnetics, vol. 5, no. 3, p. 42, 2016.

[7] C. Baccouch, et al., "Patch Antenna on a Solar Cell for Satellite Communications," International Journal on Communications Antenna and Propagation, vol. 6, no. 6, pp. 348-353, 2016.

[8] C. Baccouch, et al., "Leaf-shaped solar cell antenna for Energy Harvesting and RF Transmission in ku-band," Advances in Science, Technology and Engineering Systems Journal, vol. 2, no. 6, pp. 130-135, 2017.

[9] Roo-Ons M. J., et al., "Transparent Patch Antenna on a-Si tTin-film Glass Solar Module," Electronics Letters, vol. 47, no. 2, p. 85, 2011.

[10] Sheikh S. and Shokooh-Saremi M., "Rectangular Meshed Patch Antenna Integrated on silicon Solar Cell," 23rd Iranian Conference on Electrical Engineering, Tehran, Iran, 2015, pp. 202-206.

[11] M. Danesh and J. R. Long, "An autonomous wireless sensor node incorporating a solar cell antenna for energy harvesting," IEEE Transactions on Microwave Theory Technology, vol. 59, no. 12, pp. 3546-3555, 2011.

[12] C. Baccouch, et al., "Design of a Compact Meshed Antennas for 5G Communication Systems," International Journal of Electronics and Communication Engineering, vol. 13, no. 11, pp. 721-725, 2019.

[13] G. Clasen and R. Langley, "Meshed Patch Antenna," IEEE Transaction on Antennas and Propagation, vol. 52, no. 6 , pp. 1412-1416, 2004.

[14] W. C. Brown, "Performance characteristics of the thin-film, etched circuit Rectenna," in IEEE MTT-S International Microwave Symposium Digest, San Francisco, pp. 365-367, 1984.

[15] Ji-Yong P., et al., "A Rectenna Design with Harmonic-Rejecting Circular-Sector Antenna," IEEE Antennas and Wireless Propogation Letters, vol. 3, pp. 52-54, 2004.

[16] C. K. Chin, et al., "Design of a 5.8-GHz Rectenna Incorporating a New Patch Antenna," IEEE Antennas and Wireless Propagation Letters, vol. 4, pp. 175-178, 2005.

[17] R. K. Yadav, et al., "Rectennas design development and applications," International Journal of Engineering Science and Technology (IJEST), vol. 3, no. 10, pp. 7823-7841, 2011.

[18] L. W. Epp, et al., "A Compact Dual-Polarized 8.51-GHz Rectenna for High-Voltage (50 V) Actuator Applications," IEEE Transactions on Microwave Theory Technology, vol. 48, no. 1, pp. 111-120, 2000.

[19] M. Bozzetti, et al., "Analysis and Design of a Solar Rectenna," 2010 IEEE International Symposium on Industrial Electronics (ISIE), 2004, pp. 2001-2004.

[20] S. Joshi and G. Moddel, "Simple Figure of Merit for Diodes in Optical Rectennas," IEEE Journal of Photovoltaics, vol. 6, no. 3, pp. 668-672, 2016.

[21] S. Joshi, et al., "Infrared Optical Response of Geometric Diode Rectenna Solar Cells," 2012 38th IEEE Photovoltaic Specialists Conference, Austin, TX, 2012, pp. 002976-002978.

[22] Z. Zhu, et al., "Optical Rectenna Solar Cells Using Graphene Geometric Diodes," 2011 37th IEEE Photovoltaic Specialists Conference, Seattle, WA, 2011, pp. 002120-002122. 
[23] S. Joshi and G. Moddel, "Efficiency limits of rectenna solar cells: Theory of broadband photon-assisted tunnelin," Applied Physics Letters, vol. 102, p. 083901, 2013.

[24] E. H. Shah, et al., "A Study of Electrical Resistance in Carbon Nanotube-Insulator-Metal Diode Arrays for Optical Rectenna," IEEE Transactions on Nanotechnology, vol. 16, no. 2, pp. 230-238, 2017.

[25] S. Grover, et al., "Quantum theory of operation for rectenna solar cells," Journal of Physics D: Applied Physics, vol. 46, no. 13, pp. 1-7, 2013.

\section{BIOGRAPHIES OF AUTHORS}
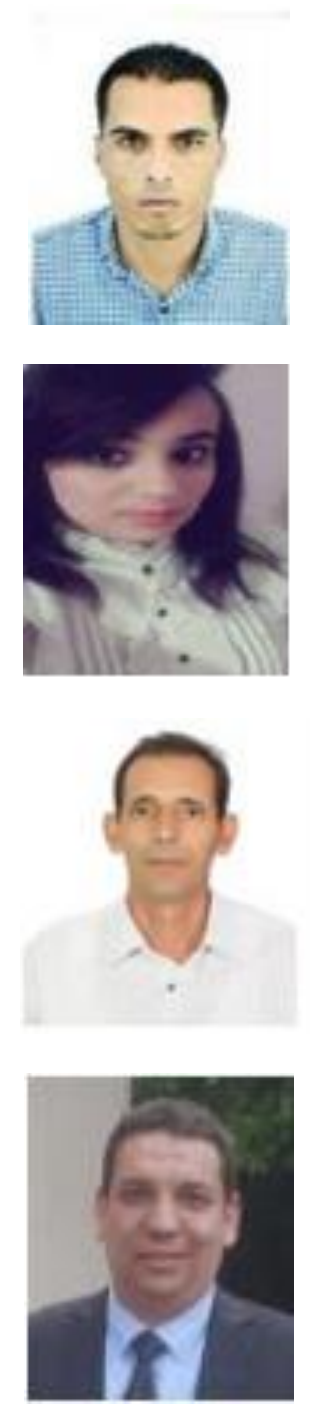

Chokri Baccouch was born in Gabes Tunisia, in 1988. He received the $\mathrm{PhD}$ in Telecommunications from the National School of Engineering of Tunis (ENIT), Tunisia, in 2018. He received the National diploma in engineering Telecommunications and Networks from the National School of Engineering of Gabes (ENIG), Tunisia, in 2012. His field of activity is computer science, 5G, connected objects, IoT and sensor networks. His research interests propagation in antennas microstrip, energy harvesting, IoT.

Chayma Bahhar was born in Gabes Tunisia, in 1994. PhD Student in Electrical engineering from the National School of Engineering of Gabes (ENIG). He received the M.S. degree in Electronics and Telecommunications from the Higher Institute of Computer Science and Multimedia of Gabes in 2019. His research interests propagation in optical rectennas, energy harvesting, IoT.

Hedi Sakli is born in Tunisia in 1966. He received the M.S. degree in High Frequency Communication Systems from Marne-La-Valley University, France in 2002, a PhD degree in 2009 and HDR degree in 2014 in telecommunications from the National Engineering School of Tunis, Tunis El Manar University, Tunisia. He is since 2010 assistant professor at the University of Gabes. He is the author of more than 30 articles. His research interests propagation in anisotropic media, Ferrite and metamaterials, numerical methods in electromagnetics and antennas.

Nizar Sakli is born in Tunisia in 1981. President of EITA Consulting in Paris (France). His field of activity is computer science, $5 \mathrm{G}$, connected objects, IoT and sensor networks. 